\title{
Systolic time intervals in chronic severe anaemia and effect of diuretic and digitalis
}

\author{
E R WARRIER, K G BALAKRISHNAN, K SANKARAN, G D GUPTA \\ From the Section of Cardiology, Department of Medicine, Fawahar Lal Institute of \\ Postgraduate Medical Education and Research, Pondicherry, India
}

SUMMARY Systolic time intervals were measured from simultaneous high speed recordings of the electrocardiogram, phonocardiogram, and carotid artery pulse in 15 men with chronic severe anaemia not in heart failure and with a normal heart size, and in 15 normal men. Heart rates, electromechanical systole (QS2), pre-ejection period index (PEPI), left ventricular ejection time index (LVETI), and the ratio of pre-ejection period to left ventricular ejection time (PEP/LVET) did not differ significantly in the two groups.

After the intravenous administration of frusemide in 10 of the anaemic patients, the pre-ejection period index was prolonged, the PEP/LVET ratio increased, heart rate increased, and the left ventricular ejection time index shortened. Intravenous digoxin did not alter the QS2 interval and heart rate significantly in the anaemic subjects. Left ventricular function in chronic severe anaemia as measured by systolic time intervals does not differ from that of normal controls. The effect of frusemide on the systolic time intervals is explained as an effect of the fall in preload, bringing cardiac function further down on the ascending limb of the Frank-Starling curve. Other related studies are discussed.

Systolic time intervals, as measures of left ventricular performance, have been widely used. ${ }^{12}$ Alterations have been noted not only in heart failure, ${ }^{3}$ but also in the absence of clinical heart failure in subjects with diabetes mellitus, ${ }^{4}$ chronic alcoholism, ${ }^{5}$ and chronic severe anaemia. ${ }^{67}$ The findings in anaemia, however, have been conflicting, and this study was therefore undertaken to repeat them.

\section{Subjects and methods}

The study was conducted in a group of 15 men with chronic severe anaemia (haemoglobin less than $4 \mathrm{~g} / 100$ $\mathrm{ml}$ ) caused by hookworm infestation, and in a control group of 15 normal men (haemoglobin more than 13 $\mathrm{g} / 100 \mathrm{ml})$.

The subjects studied underwent a complete clinical examination to rule out any other relevant disease.

The systolic time intervals were measured from a simultaneous recording of the electrocardiogram, phonocardiogram, and carotid artery pulse tracing on a multichannel direct writing machine (Siemens Mingograf Cardirex 6T) at a paper speed of $100 \mathrm{~mm}$ per

Present address: Department of Medicine, Maulana Azad Medical College, New Delhi-110002 (India).

Received for publication 10 November 1980 second. The recordings were taken in the basal postabsorptive state between 9 and $11 \mathrm{am}$. All patients had a normal heart size on the chest $x$-ray film. None had congestive heart failure or evidence of atrioventricular or intraventricular conduction defects. All were in sinus rhythm.

The electrocardiographic lead II was used since this showed the onset of ventricular depolarisation clearly in all cases.

The phonocardiogram was recorded with a piezoelectric crystal microphone (EMI 25, ElemaSchonander) over the praecordium in a position optimal for recording the first high frequency vibrations of the second heart sound.

The carotid arterial pulse tracing was recorded over the right carotid artery in held expiration with an infraton pulse receptor (EMT $439 \mathrm{R}$ ElemaSchonander). The device was held in place manually and the tracing watched on an oscilloscope, the recording being taken only when the carotid notch was clearly evident.

In 10 of the patients with anaemia, after the basal records were obtained, frusemide $80 \mathrm{mg}$ was given intravenously. After two hours the amount of urine passed was noted and the recordings were repeated. During this period the patient was at rest. 
In six of these patients the recordings were repeated after an interval of two days and digoxin $1 \mathrm{mg}$ was then given intravenously. The recordings were repeated an hour later, the patient being monitored on an oscilloscope meanwhile.

The following intervals were measured directly.

(1) Total electromechanical systolic interval (QS2)-from the onset of the $Q$ wave to the first high frequency vibrations of the second heart sound.

(2) The left ventricular ejection time-from the beginning of the upstroke of the carotid pulse to the trough of the incisura.

(3) The RR interval, for heart rate.

The pre-ejection phase was calculated by subtracting the left ventricular ejection time from QS2.

The ratio of PEP/LVET was calculated from the above values. The measurements were made on 10 consecutive beats and the mean was taken. The preejection period and left ventricular ejection time were corrected for heart rate using the regression equation of Weissler $e t a l{ }^{3}$ and the suffix (I) identifies these derived indices.

Statistically significant differences between control and anaemic subjects were assessed by Student's t test, but those in the anaemic subjects before and after frusemide and digoxin were assessed by the paired $t$ test. The conventional level of significance $(\mathbf{p}<0.05)$ was used.

\section{Results}

Table 1 compares the observations made in the control group with those in the anaemic group. No significant differences were observed in the heart rate, QS2 preejection period index, left ventricular ejection time index, and PEP/LVET ratio. The anaemic subjects were older than the controls but age has no influence on the pre-ejection phase and left ventricular ejection time corrected for heart rate. ${ }^{89}$

Beat to beat variability was evaluated by comparing the pre-ejection period in a random beat with the mean pre-ejection period of 10 beats, in 10 patients. This variability was not significant statistically. We have previously established in our laboratory that measurements of the effects of such variability on systolic time intervals do not differ in statistical significance from others in the same subject when done under basal conditions on different days (unpublished data). Further evidence of the accuracy of our measurements is afforded by their return to previous basal values two to three days after the administration of the diuretic.

After the administration of frusemide, we observed a very highly significant prolongation of the pre-ejection period index and PEP/LVET ratio $(p<0.001)$, a highly significant shortening of left ventricular ejection time index $(p<0.01)$, and a significant increase in heart rate $(p<0.05)$ (Table 2). The volume of urine passed by the patients in the two hours after frusemide ranged from 600 to $750 \mathrm{ml}$.

In six of the patients to whom digoxin was given, there were no significant changes in QS2, left ventricular ejection time index, pre-ejection period index, PEP/LVET ratio, and heart rate (Table 3).

\section{Discussion}

Systolic time intervals are accepted as measures of left ventricular contractility and pump function. ${ }^{3}$ The preejection period, in particular, has been shown to have a significant correlation with internally measured left ventricular $\mathrm{dP} / \mathrm{dt}$ and with other indices of left ventricular performance such as cardiac index, stroke volume index, left ventricular end-diastolic pressure, and ejection fraction. ${ }^{10}$ The occurrence of left ventricular failure in chronic severe anaemia is still a matter for controversy. Some cases of congestive heart failure in uncomplicated anaemia have been reported, ${ }^{11} 12$ but these have been clinical descriptions unsupported by haemodynamic data.

Guleria and co-workers ${ }^{13}$ undertook pulmonary

Table 1 Comparison of data in control and anaemic subjects

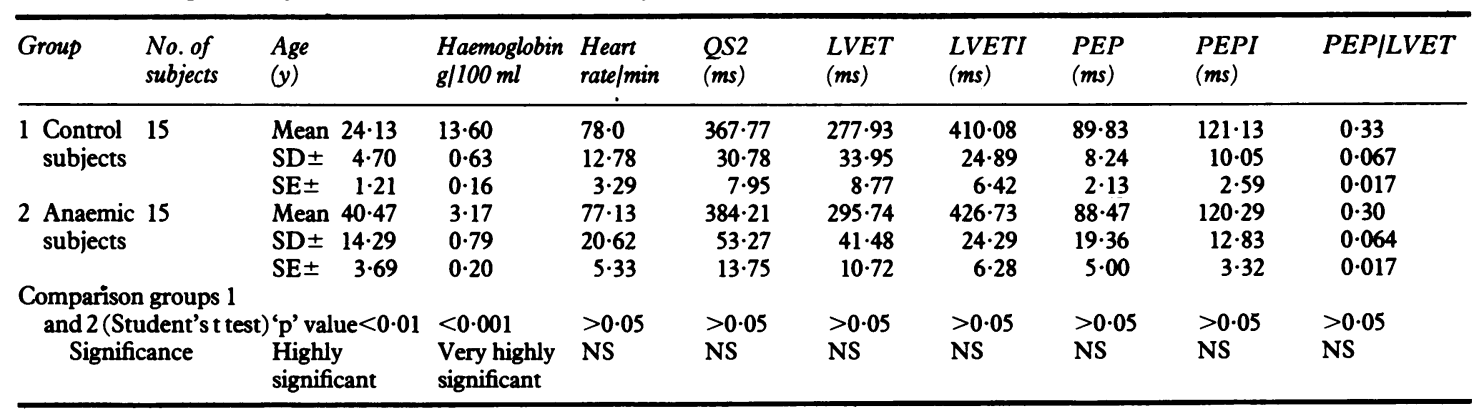

Abbreviations as in text.

NS, not significant. 
Table 2 Effect of $80 \mathrm{mg}$ frusemide intravenously on systolic time intervals in anaemic subjects

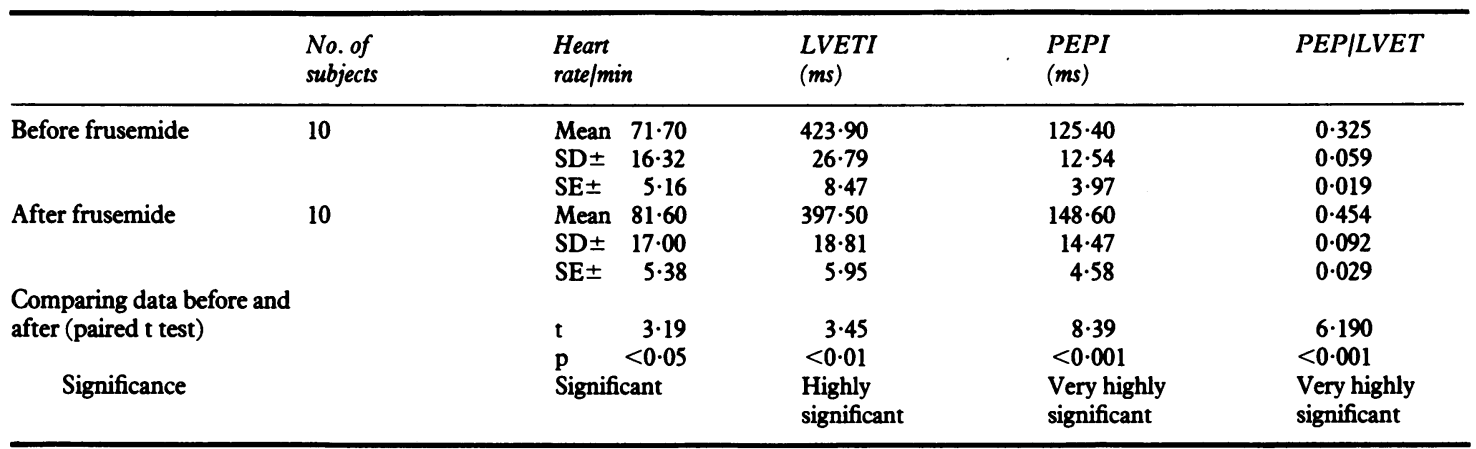

Abbreviations as in text.

Table 3 Effect of $1 \mathrm{mg}$ digoxin intravenously on systolic time intervals in anaemic subjects

\begin{tabular}{|c|c|c|c|c|c|c|}
\hline & $\begin{array}{l}\text { No. of } \\
\text { subjects }\end{array}$ & $\begin{array}{l}\text { Heart } \\
\text { rate/min }\end{array}$ & $\underset{(m s)}{Q S 2 I}$ & $\begin{array}{l}\text { LVETI } \\
\text { (ms) }\end{array}$ & $\begin{array}{l}P E P I \\
(m s)\end{array}$ & PEP/LVET \\
\hline \multirow[t]{2}{*}{ Before digoxin } & 6 & $\begin{array}{lc}\text { Mean } & 71 \cdot 5 \\
\mathrm{SD} \pm & 7 \cdot 15\end{array}$ & $\begin{array}{r}544.06 \\
33.82\end{array}$ & $\begin{array}{r}419 \cdot 30 \\
26 \cdot 85\end{array}$ & $\begin{array}{r}125 \cdot 70 \\
15 \cdot 93\end{array}$ & $\begin{array}{l}0.326 \\
0.050\end{array}$ \\
\hline & & $\mathrm{SE} \pm \quad 2.92$ & $13 \cdot 81$ & 10.96 & 6.50 & 0.020 \\
\hline \multirow[t]{3}{*}{ After digoxin } & 6 & Mean $77 \cdot 5$ & $526 \cdot 60$ & $402 \cdot 60$ & $122 \cdot 30$ & 0.344 \\
\hline & & $S D \pm 13.97$ & $30 \cdot 11$ & $24 \cdot 33$ & $9 \cdot 28$ & 0.032 \\
\hline & & $\mathrm{SE} \pm \quad 5.70$ & $12 \cdot 29$ & 9.93 & $3 \cdot 79$ & 0.015 \\
\hline Comparing data before & & t value 1.55 & 0.99 & 0.828 & 0.575 & 0.648 \\
\hline and after (paired t test) & & $p$ value $>0.05$ & $>0.05$ & $>0.05$ & $>0.05$ & $>0.05$ \\
\hline Significance & & NS & NS & NS & NS & iNS \\
\hline
\end{tabular}

Abbreviations as in text.

NS, not significant.

function studies in patients with severe anaemia and found an increase in pulmonary capillary blood volume. This they interpreted as being the result of pulmonary congestion caused by heart failure but the rise was not statistically significant. Moreover, Rankin et al. ${ }^{14}$ have reported decreased pulmonary capillary blood volume in chronic anaemia.

The concept of non-cardiac circulatory congestion has been postulated by Eichna et al. ${ }^{15}$ and Eichna, ${ }^{16}$ who suggested that both systemic and pulmonary vascular congestion may arise on a non-cardiac basis to produce a clinical syndrome that closely simulates congestive heart failure.

Our data conclusively show that there is no left ventricular dysfunction in uncomplicated severe anaemia that can be shown by measurement of systolic time intervals. The response to the intravenous administration of frusemide further supports this contention. The pronounced prolongation of the pre-ejection period index and increase in PEP/LVET ratio after this drug shows that the heart was performing normally beforehand and was on the ascending limb of the Frank-Starling curve. Prolongation of the pre-ejection period, reduction in left ventricular ejection time, and increase in PEP/LVET ratio are known to occur with heart failure. ${ }^{3}$ If subclinical heart failure had been present one would have expected an improvement of left ventricular function after the diuresis, manifested by shortening of the pre-ejection period. The reduction in blood volume consequent upon the diuresis must have decreased the filling pressures and the compensatory mechanisms that maintained the cardiac output. That right sided filling pressure may fall drastically with frusemide has been shown by us ${ }^{17}$ in a more recent study on comparable anaemic subjects.

In heart failure, after digoxin administration, there is shortening of all the systolic time intervals, the effect being more obvious than in normals. ${ }^{18}$ The effect on the QS2 interval is perhaps the most consistent of these changes and was not observed in our six patients.

Abdullah and co-workers ${ }^{7}$ also found no significant differences in systolic time intervals in patients with moderate anaemia without congestive heart failure when compared with normal controls. We have no explanation to offer for the contrary observations of Manchanda and co-workers, ${ }^{6}$ reporting on severely anaemic subjects, who found prolongation of the preejection period alone in the presence of a normal ejection time index, since it has been shown that in heart failure total electromechanical systole is unchanged, a 
prolonged pre-ejection period being associated with a shortened left ventricular ejection time. ${ }^{3}$ Certainly, in diabetics and chronic alcoholic subjects, subclinical left ventricular dysfunction has been accompanied by such findings. ${ }^{45}$

In chronic severe anaemia the haemodynamic changes are likely to be those associated with enhanced rather than reduced ventricular function. Animal studies have shown a significant increase in contractility in dogs with dextran-induced normovolaemic anaemia ${ }^{19}$ and a shortened pre-ejection period with an increased left ventricular ejection time have been shown in patients with chronic severe anaemia, ${ }^{7}$ the latter change being thought to be the consequence of raised stroke volume. Our results, though not showing increased contractility, conclusively indicate that subclinical left ventricular failure does not occur in chronic severe anaemia.

\section{References}

1 Weissler AM, Harris WS, Schoenfeld CD. Bedside techniques for the evaluation of ventricular function in man. Am f Cardiol 1969; 23: 577-83.

2 Weissler AM, Garrard CL. Systolic time intervals in cardiac disease. Mod Concepts Cardiovas Dis 1971; 40: $1-4$.

3 Weissler AM, Harris WS, Schoenfeld CD. Systolic time intervals in heart failure in man. Circulation 1968; 37: 149-59.

4 Ahmed SS, Jaferi GA, Narang RM, Regan TJ. Pre-clinical abnormality of left ventricular function in diabetes mellitus. Am Heart f 1975; 89: 153-8.

5 Wu CF, Sudhakar M, Jaferi G, Ahmed SS, Regan TJ. Pre-clinical cardiomyopathy in chronic alcoholics: a sex difference. Am Heart F 1976; 91: 281-6.

6 Manchanda SC, Bansal R, Soni V, Roy SB. Systolic time intervals in chronic severe anaemia. Indian Heart $\mathcal{F}$ 1974; 26: 32-4.

7 Abdullah AK, Siddiqui MA, Tajuddin M. Systolic time intervals in chronic anemia. Am Heart f 1977; 94: 287-91.
8 Harrison TR, Dixon K, Russell RO, Jr, Bidwai PS, Coleman HN. The relation of age to the duration of contraction, ejection and relaxation of the normal human heart. Am $\bar{H}$ eart $\mathcal{F}$ 1964; 67: 189-99.

9 Willems JL, Roelandt J, De Geest H, Kesteloot H, Joossens JV. The left ventricular ejection time in elderly subjects. Circulation 1970; 42: 37-42.

10 Mcconahay DR, Martin CM, Cheitlin MD. Resting and exercise systolic time intervals: correlation with ventricular performance in patients with coronary artery disease. Circulation 1972; 45: 592-601.

11 Bartels EC.Anaemia as the cause of severe congestive heart failure: report of a case. Ann Intern Med 1937; 11: $400-4$.

12 Somers K. Acute reversible heart failure in severe irondeficiency anemia associated with hookworm infestation in Ugandan Africans. Circulation 1959; 19: 672-5.

13 Guleria JS, Pande JN, Markose MM, Gupta RG, Jain BP. Pulmonary function in chronic severe anaemia. Clin Sci 1971; 40: 317-25.

14 Rankin J, McNeill RS, Forster RE. The effect of anemia on the alveolar-capillary exchange of carbon monoxide in man. $\mathcal{F}$ Clin Invest 1961; 40: 1323-30.

15 Eichna LW, Farber SJ, Berger AR, Rader B, Smith WW, Albert RE. Non-cardiac circulatory congestion stimulating congestive heart failure. Trans Assoc Am Physicians 1954; 67: 72-85.

16 Eichna LW. The George E Brown Memorial Lecture. Circulatory congestion and heart failure. Circulation 1960; 22: 864-86.

17 Gupta GD, Kundu AK. Circulatory overload and oxygen delivery in chronic severe anaemia (in preparation).

18 Weissler AM, Schoenfeld CD. Effect of digitalis on systolic time intervals in heart failure. Am $\mathcal{Y}$ Med Sci 1970; 259: 4-20.

19 Escobar E, Jones NL, Rappaport E, Murray JF. Ventricular performance in acute normovolemic anemia and effects of beta blockade. Am F Physiol 1966; 211: 877-84.

Requests for reprints to Professor G D Gupta, Maulana Azad Medical College, New Delhi 110002, India. 